\title{
Adherencias abdominales postquirúrgicas en equinos: patofisiología, prevención y tratamiento
}

\author{
Post-surgical abdominal adhesions in horses: pathophysiology, prevention and treatment
}

\author{
M Wernerb, JS Galecio ${ }^{\mathrm{a}}$, H Bustamante ${ }^{\mathrm{a}, \mathrm{b}^{*}}$ \\ anstituto de Ciencias Clínicas Veterinarias, Facultad de Ciencias Veterinarias, \\ Universidad Austral de Chile, Valdivia, Chile. \\ bBiomedical and Veterinary Science Graduate Program, Virginia-Maryland Regional College of Veterinary Medicine,
} Virginia Tech, USA.

\begin{abstract}
SUMMARY
Despite the great number of human and veterinary medicine research, abdominal adhesions are still a big concern and a frequent complication for surgeons. The development of abdominal adhesions is a complex and dynamic process that involves a series of different mechanisms that start with an inflammatory process and tissue damage, followed by a fibrinogenic and fibrinolytic unbalance and ends with a change from fibrin deposit to fibrous tissue. In horses, after small intestine surgeries, adhesion incidence ranges from 14 to $22 \%$. It is the most frequent cause of recurrent abdominal pain and the second cause for repeat celiotomy. Nevertheless, when all equine abdominal surgeries are included, the incidence of postoperative adhesions approximates 5\%. A better understanding of the cellular mechanisms of adhesion formation and reformation should help to develop better prevention methods. Currently, a variety of prevention measures and treatments, most of them aiming to reduce or avoid adhesions formation, are used in veterinary medicine. The aim of this review is to gather most of the available information and the latest research explaining the pathophysiology, prevention and treatment of abdominal adhesions in horses.
\end{abstract}

Palabras clave: equinos, adherencias abdominales, postquirúrgicas.

Key words: equine, abdominal adhesions, post-surgical.

\section{INTRODUCCIÓN}

Las enfermedades gastrointestinales continúan siendo una de las mayores preocupaciones en la industria de los equinos y una gran proporción de caballos son derivados a centros quirúrgicos debido a desórdenes abdominales (Smith y col 2005). Estas patologías incluyen desórdenes de la motilidad y obstructivos, siendo comunes tanto en medicina humana como en medicina veterinaria. Estas alteraciones tienden a ser clínicamente importantes en ambas disciplinas, con un extensivo impacto en la práctica veterinaria así como también en la salud pública humana (Hudson y Dunlop 2005). Se ha descrito que la formación de adherencias es la causa más común de episodios repetidos de cólico luego de cirugías de intestino delgado en caballos y es la segunda causa más común de celiotomías repetidas en equinos después de cirugías de cólico por otras causas (Baxter y col 1989, Parker y col 1989, Baxter 1991, Mair y Edwards 2003). Estos estudios contrastan con Gorvy y col (2008), quienes no encontraron evidencia que sugiriera a partir del hecho de que las lesiones de intestino delgado o grueso en una primera cirugía lleven a la formación de adherencias. Adicionalmente, se detalla que posterior a

Aceptado: 17.12.2008.

* hbustamante@uach.cl cirugías de intestino grueso el 36\% de las adherencias produjeron obstrucción de intestino delgado. Varios estudios realizados en los últimos diez años describen que las adherencias postquirúrgicas se presentan entre un $6 \%$ y un $27 \%$ en equinos con obstrucción de intestino delgado o como un hallazgo de una segunda cirugía de abdomen (Freeman y col 2000, Mair y Smith 2005, Gorvy y col 2008).

En este sentido, estudios realizados previamente indican un $14 \%$ de adherencias postquirúrgicas (Phillips y Walmsley 1993); por otro lado, Baxter y col (1989) indican que un $22 \%$ de adherencias se presentan posterior a cirugías gastrointestinales, detallando además en su estudio que probablemente se haya subestimado la ocurrencia total de adherencias posterior a cirugías de intestino delgado, producto de que en equinos las adherencias intraabdominales que involucran el intestino grueso, incluyendo el ciego, generalmente no llevan a signos clínicos de dolor abdominal. Por su parte, MacDonald y col (1989) estiman que la causa de muerte más común (26\%) en casos de cirugías de intestino delgado es la formación de adherencias y episodios repetidos de cólico. Vachon y Fischer (1995) establecen en un $6 \%$ la formación de adherencias en casos en donde el intestino delgado se encarcela en el foramen epiploico. Sin embargo, el diseño de los distintos estudios es tan variado que hace inapropiada una comparación entre ellos (Gorvy y col 2008). 
Se ha mencionado una serie de factores de riesgo en la formación de adherencias; cualquier condición inflamatoria dentro de la cavidad peritoneal puede afectar el sistema que deposita y lisa la fibrina y de esa manera predisponer a la formación de adherencias fibrosas (Hay y Mueller 1998). Dentro de los factores que determinan la presentación de adherencias se encuentra el manejo de la técnica anastomótica de intestino (Southwood y col 1997). Al respecto, Sullins y col (1985) determinaron que la eversión de la mucosa aumenta la formación de adherencias durante el período postoperatorio inicial. Otros factores que predisponen a la formación de adherencias son el íleo paralítico postquirúrgico y laparotomías repetidas (Parker y col 1989, Mair y Smith 2005). Por otra parte, Gorvy y col (2008) observaron que el riesgo de desarrollar adherencias disminuye cuando existe un aumento en el volumen globular aglomerado (VGA) y frecuencia cardiaca, lo que sugiere que la formación de adherencias no estaría relacionada con endotoxemia. En el mismo sentido, Collatos y col (1994) reportaron que eventos ocurridos en el sistema vascular no se ven reflejados en la cavidad peritoneal. Otra variable que podría relacionarse con la formación de adherencias son las proteínas totales, las cuales muestran una relación no lineal con el riesgo de formación de adherencias. Esto sugiere que una concentración óptima de proteínas plasmáticas de aproximadamente $63 \mathrm{~g} / \mathrm{L}$ minimiza el riesgo de adherencias, con un incremento en el riesgo de presentación de ellas cuando las concentraciones son mayores o menores a lo reportado como normal para la especie (Gorvy y col 2008). Otro factor de riesgo es la edad de animal, sugiriéndose que los potrillos son más susceptibles de desarrollar adherencias (Lundin y col 1989). Cable y col (1997) estiman en su estudio que un 33\% de los potrillos examinados después de la cirugía original presentaron evidencia de adherencias intraabdominales y un $16 \%$ presentó adherencias que causaron problemas clínicos. Además, Singer y Livesey (1997) indican que un $10 \%$ de muertes postoperatorias se debería a la formación de adherencias, valor de mortalidad menor al indicado para potrillos por Vatistas y col (1996), el cual sería de aproximadamente un $17 \%$.

De manera interesante, cabe mencionar que las adherencias abdominales se conocen por al menos 1.500 años, siendo descritas por Talmud en Babilonia en el 440 a.C. Algunos datos sugieren que los antiguos egipcios, conocidos por sus detalladas descripciones de la anatomía humana, habrían descrito la presentación de adherencias pélvicas siglos antes que esto. A partir de 1880, comienzan a aparecer las primeras publicaciones sobre el uso de adyuvantes para la prevención de adherencias. Lo que sigue en los siguientes 100 años es una plétora de reportes científicos y anécdotas que describen el uso de fluidos amnióticos, rumen bovino, peritoneo de tiburón, vejiga de peces, humor vítreo de terneros, variadas gomas, lubricantes, fluidos, geles, polímeros, barreras físicas y una serie de métodos de separación mecánica para prevenir las adherencias. El objeto de esta detallada descripción histórica es el de enfatizar que las adherencias son descritas desde hace mucho tiempo y los avances que se están haciendo son para entender la fisiología básica de su formación (Becker y Stucchi 2004).

Las membranas serosas de las cavidades peritoneal, pleural y pericárdica son derivaciones embriológicas similares y se encuentran recubiertas por una capa de células mesoteliales, las cuales se mantienen unidas a una membrana basal (Cheong y col 2001). La membrana peritoneal está compuesta por una monocapa de células mesoteliales de origen mesenquimal sobre una membrana basal continua anclada en el submesotelio (van der Wal y Jeekel 2007). Este último consiste en una matriz extracelular (MEC) compuesta de diferentes tipos de colágeno, glicoproteínas, glicosaminoglicanos y proteoglicanos (Cheong y col 2001). Las células mesoteliales presentan una población homogénea con apariencia aplanada, estirada y escamosa o cuboidal (van der Wal y Jeekel 2007). La superficie luminal de las células mesoteliales presenta numerosos microvellos, los cuales aumentan la superficie funcional para el intercambio entre células mesoteliales y la cavidad peritoneal. Sin embargo, estos microvellos son estructuras lábiles y el número de éstos presentes en cada célula varía dependiendo de las condiciones fisiológicas y patológicas (Mutsaers y col 1996). Las células mesoteliales poseen además cilios en su superficie apical, los cuales son cinco veces más largos que los microvellos adyacentes; la cantidad de cilios en la superficie mesotelial aumenta con incrementos en la densidad celular, lo cual sugiere que ellos juegan un rol esencial en la polaridad de las células mesoteliales y en la adhesión célula-célula (van der Wal y Jeekel 2007). Clásicamente, las funciones primarias atribuidas al mesotelio son proveer una barrera de protección e interfase sin fricción para movimientos libres de aposición de órganos y tejidos. Recientemente, se ha descubierto que este tejido juega un rol en el transporte de fluidos y células, iniciación y resolución del proceso inflamatorio, reparación tisular, lisis de depósitos de fibrina y protección contra microorganismos invasores y, posiblemente, diseminación de tumores (Mutsaers 2002, 2004). La parte intermedia y visceral de las membranas serosas no sólo provee de un mecanismo de suspensión elástico y adaptable, sino que también forma un lecho para estructuras sanguíneas, linfáticas y nerviosas, las que proporcionan vascularización e inervación, encontrándose estas estructuras en el espacio subseroso (Cheong y col 2001, Foley-Comer y col 2002). La superficie libre de las membranas serosas es lisa y está lubricada por una pequeña cantidad de líquido seroso; de aquí que las vísceras se puedan deslizar sobre la pared de las cavidades o unas sobre otras, con la menor cantidad posible de fricción (Didio 1994). La difusión y reabsorción del fluido ocurre libremente a través del mesotelio y estroma submesotelial (Cheong y col 2001). 
El peritoneo que recubre el interior del abdomen está compuesto por tejido conectivo bajo una capa simple de células mesoteliales, separado por una membrana basal. Estas capas proveen un soporte externo a la capa muscular del intestino y mantienen una capa lubricada en la superficie serosa (Eggleston y Mueller 2003). En equinos, el líquido peritoneal es un transudado simple y de poco volumen, el cual es producido por el peritoneo semipermeable. Aproximadamente $60 \mathrm{ml}$ de líquido peritoneal son producidos por hora, pero la cavidad peritoneal normalmente contiene sólo una pequeña cantidad de este líquido (Browning 2005). El líquido peritoneal normalmente contiene muchas de las proteínas plasmáticas, dentro de las cuales el fibrinógeno interviene durante el proceso inflamatorio intraperitoneal, especialmente en el período intra y postoperatorio, en donde se forman las adherencias (Duron 2007). De acuerdo a Hanson y col (1992), el líquido peritoneal refleja el estado patofisiológico de las superficies mesoteliales parietales y viscerales, por lo cual manipulaciones adicionales del peritoneo asociadas a resección y anastomosis de dos segmentos de intestino tendrían pequeñas consecuencias comparado con el trauma inducido en una celiotomía exploratoria. El peritoneo se invierte sobre sí mismo para formar dos estructuras, el omento y el mesenterio, los cuales contienen una gran cantidad de vasos linfáticos y sanguíneos. En mamíferos machos, forman un espacio cerrado, mientras que en hembras existe una potencial comunicación al exterior vía cuernos uterinos. El peritoneo parietal se encuentra inervado por ramas de nervios espinales y contiene nociceptores térmicos, químicos y mecánicos (Duron 2007), los cuales son capaces de procesar estímulos dolorosos agudos localizados (Hollinshead 1953, Browning 2005). El peritoneo visceral, en contraste, está inervado por aferentes simpatéticos y reacciona a estímulos producidos por distensión, estiramiento, isquemia e inflamación (Browning 2005). Las adherencias se encuentran bien vascularizadas, independiente de su madurez, ubicación o patología intraperitoneal. Las fibras nerviosas, consistentes en axones mielínicos y amielínicos, son comunes de encontrar en las adherencias. El rol de las adherencias en la etiología del dolor abdominal es aún controversial, pero la presencia de fibras nerviosas dentro de éstas sostiene la teoría de que ellas son capaces de conducir estímulos nociceptivos (Herrick y col 2000).

La mayoría de los eventos patofisiológicos relacionados con el desarrollo de las adherencias intraabdominales se encuentran poco descritos para la especie equina en particular; debido a esta razón la mayor parte de la información presentada a continuación hace referencia a diversos estudios, principalmente llevados a cabo tanto in vitro como in vivo en animales de experimentación y humanos. Estos resultados son extrapolados a la especie equina de la mejor forma posible de acuerdo a lo reportado por la literatura científica veterinaria para dicha especie (Fubini 1990, White 1993, Mueller 2002).

\section{PATOFISIOLOGÍA}

Las adherencias son bandas de material fibrinoso que se originan en la superficie de una membrana serosa y forman una conexión con una superficie opuesta (Semrad 1999); se clasifican básicamente en adherencias de tipo inflamatorio y postquirúrgicas. Las adherencias inflamatorias se presentan después de procesos inflamatorios intraabdominales. En cambio, las adherencias postquirúrgicas son la consecuencia resultante de un daño a la superficie tisular, que posterior a incisiones, cauterización, sutura $\mathrm{u}$ otras formas de trauma se fusionan para formar tejido cicatrizal (Liakakos y col 2001). No obstante, las adherencias pueden ser beneficiosas debido a su habilidad de proveer una fuente adicional de sangre a la serosa o intestino isquémico (Baxter 1991). Igualmente, adherencias perianastomóticas pueden prevenir fugas desde las líneas de sutura y aislar desechos inflamatorios, previniendo así una peritonitis generalizada (Mueller y col 2000 ${ }^{\mathrm{b}}$ ).

Diversas alteraciones inflamatorias del mesotelio peritoneal promueven el proceso de formación de adherencias a través del inicio de un estado procoagulativo inmediato, caracterizado por la secreción de exudado serofibrinoso y deposición de fibrina (Ellies 1962, Holmdahl 1997). La formación de adherencias finalmente es el resultado de un desbalance entre los procesos de fibrinogénesis y fibrinólisis. La prevalencia de una de éstas sobre la otra produce la variabilidad de la respuesta a adherencias por parte de diferentes pacientes (Di Filippo y col 2006). Durante una cirugía, el daño mesotelial inicial expone una superficie limpia y acelular que sirve como nido para la formación de adherencias del tipo tejido-tejido. Este daño y la ruptura de la matriz submesotelial ocurren junto con la activación de la cascada de la coagulación y la deposición de fibrina en el sitio dañado (Boland y Weigel 2006). Las injurias quirúrgicas del tejido reducen o eliminan el flujo sanguíneo, produciendo isquemia, lo cual lleva a la persistencia de la matriz de fibrina, siendo gradualmente reemplazada por tejido de granulación, el cual atrae la presencia de macrófagos, fibroblastos y células gigantes. Durante este proceso el tejido de granulación se caracteriza por poseer variables cantidades de eritrocitos separados por bandas o masas condensadas de fibrina, las cuales se encuentran cubiertas con dos o tres capas de células aplanadas que contienen un infiltrado de células mononucleares (diZerega y Campeau 2001). El mecanismo involucrado en la regeneración mesotelial es controversial y muchas hipótesis se han propuesto para el origen de las células del mesotelio en regeneración (Foley-Comer y col 2002). Actualmente, Duron (2007) señala que se manejan cuatro hipótesis al respecto, las cuales son: a) crecimiento de células periféricas, b) transformación de células mesenquimales totipotenciales subyacentes o células perivasculares en el mesotelio, c) trasplante de células mesoteliales provenientes del mesotelio de estructuras adyacentes o de 
células mesoteliales de libre flotación y d) transformación de células del líquido peritoneal.

Se ha establecido experimentalmente que el daño en el tejido peritoneal produce una reducción en la capacidad fibrinolítica y como consecuencia la formación de adherencias intraabdominales (Thompson 1998). Este sistema fibrinolítico extravascular, independiente de la circulación de la cavidad peritoneal, difiere del sistema fibrinolítico plasmático, en donde un tipo celular (células endoteliales vasculares) secreta un activador de plasminógeno tipo tejido (t-PA) y otros tipos celulares (hepatocitos, células endoteliales y células de Küpffer) son responsables de la depuración de t-PA desde la circulación sanguínea (Sitter y col 1999).

Una gran variedad de estímulos inflamatorios pueden resultar en daño peritoneal, lo cual se ha asociado a cambios histopatológicos que demuestran una clara secuencia de eventos desde el daño a la formación de adherencias (Thompson 1998). La injuria peritoneal quirúrgica, procesos inflamatorios o isquémicos llevan a una sustancial disminución del flujo sanguíneo y al crecimiento patológico de vasos sanguíneos (Cheong y col 2001), además causa la descamación de células mesoteliales, dejando un área desnuda (van der Wal y Jeekel 2007); esta fase coincide con un aumento en la permeabilidad de los vasos (Duron 2007), lo que lleva a la liberación de células y exudado inflamatorio, el cual es organizado. La invasión de fibroblastos es seguida por deposición de colágeno y formación de tejido fibroso permanente. El organismo, igualmente, posee mecanismos que contrarrestan esta deposición de fibrina, ya que las superficies mesoteliales, tales como el peritoneo, poseen actividad fibrinolítica, la cual, de no ser dañada, produce lisis de fibrina dentro del exudado inflamatorio antes de que este último se organice (Thompson 1998). Las células mesoteliales son células metabólicamente activas que participan en la inflamación serosa a través de la secreción de varios mediadores pro, anti e inmunomoduladores, dentro de los cuales se pueden incluir prostaglandinas y prostaciclinas, quemoquinas, óxido nítrico $(\mathrm{ON})$, especies nitrógeno y oxígeno reactivas, enzimas antioxidantes, citoquinas, factores de crecimiento, matriz extracelular (MEC), moléculas y productos de la cascada de la coagulación (Mutsaers 2002). Cultivos celulares mesoteliales humanos han demostrado producir grandes cantidades de activador de plasminógeno (PA), tipo tejido (t-PA) y tipo uroquinasa (u-PA), así como también su inhibidor específico, el inhibidor del activador de plasminógeno tipo 1 (PAI-1). Se reporta que las células mesoteliales no sólo sintetizan activamente PA, sino que también internalizan y degradan eficientemente t-PA y u-PA vía endocitosis mediada por receptores (Sitter y col 1999).

El funcionamiento del sistema fibrinolítico tiene como base la conversión de una proenzima, el plasminógeno, a su enzima proteolíticamente activa, la plasmina, capaz de degradar el coágulo de fibrina. La transformación de plasminógeno en plasmina activa se produce mediante la acción proteolítica de dos enzimas activadoras de plasminógeno (PA), denominadas respectivamente activador tisular de plasminógeno (t-PA) y activador del plasminógeno de tipo uroquinasa (u-PA) (Hellebrekers y col 2000, Cheong y col 2001, Mutsaers 2002, Gilabert 2005). Se cree que el t-PA es responsable primariamente de la remoción de fibrina dentro de la vasculatura a través de su específica afinidad por la fibrina. Alternativamente, u-PA se une a receptores celulares y ha sido tradicionalmente asociado con proteólisis pericelular vía degradación de componentes de la matriz celular y activación de proteasas latentes y factores de crecimiento en sitios extravasculares (Sulaiman y col 2002). A esta tendencia profibrinolítica se opone una antifibrinolítica, la cual está mediada por la acción de los inhibidores naturales de los PA, los cuales se denominan inhibidor del activador del plasminógeno tipo 1 (PAI-1) y tipo 2 (PAI-2). Existe un tercer inhibidor denominado inicialmente PAI-3 y que más tarde fue identificado como uno de los inhibidores de la proteína $\mathrm{C}$ reactiva en su forma activada (Hellebrekers y col 2000, Cheong y col 2001, Mutsaers 2002, Gilabert 2005, Renckens y col 2005). Se ha sugerido que los componentes del sistema plasmina, particularmente PAI-1, pueden ser usados como marcadores tisulares de la propensión a desarrollar adherencias postquirúrgicas, por lo que podría ser un potencial identificador de pacientes de alto riesgo (Di Filippo y col 2006). El inhibidor de PA tipo-2 (PAI-2), a diferencia de PAI-1, no es detectable en plasma y por lo tanto PAI-1 es reconocido como el mayor inhibidor sistémico de fibrinólisis (Ritchie y Booth 1998). Por otro lado, PAI-2 ha sido detectado en epidermis, tejido inflamado y placenta, siendo los tipos celulares que expresan PAI-2 queratinocitos, monocitos y trofoblastos respectivamente. Además, otros tipos celulares expresan PAI-2, incluyendo células endoteliales, células de músculo liso, fibroblastos y muchas líneas celulares transformadas. La ubicación de PAI-2 parece ser específica del tipo celular y las células endoteliales y fibroblastos mantienen PAI-2 casi exclusivamente como molécula intracelular, en cambio los monocitos tienen ambas PAI-2, intracelular y secretoria. La doble ubicación de PAI-2 refleja diferentes funciones en ambos sitios. PAI-2 secretada por monocitos modula eficientemente la migración de células mediada por u-PA, a diferencia de PAI-2 intracelular que ha demostrado prevenir la apoptosis celular (Ritchie y col 1999).

El principal PA en el peritoneo es t-PA, el cual es inhibido cuando se forma un complejo 1:1 con inhibidor de PA PAI-1. El trauma quirúrgico ha demostrado deteriorar la actividad fibrinolítica peritoneal a través de la reducción de la actividad de PA y/o aumentar la actividad de PAI-1 y PAI-2, siendo estas sustancias encontradas sólo en peritoneo inflamado (Holmdahl 1997, Wang y col 2003, Reed y col 2004, Memisoglu y col 2006, Polubinska y col 2006). El tiempo que toman los cambios fibrinolíticos, posterior a un daño quirúrgico, en pacientes sin inflamación peritoneal 
preexistente, ha sido analizado usando drenajes de líquido peritoneal, encontrándose que éste rápidamente pierde actividad del PA y esta pérdida de actividad se encuentra asociada a una detección de altos niveles de PAI-1 y 2 (Thompson 1998).

La actividad fibrinolítica es t-PA dependiente y su pérdida es el resultado de la producción de PAI- 1 y 2 por el tejido mesotelial y submesotelial. Esta producción de PAIs parece ser el resultado del estímulo de citoquinas proinflamatorias de células mesoteliales y mediadores tales como lipopolisacáridos (LPS), factor de necrosis tumoral- $\alpha$ (TNF- $\alpha$ ) e interleuquin-1 (IL-1), además de mediadores fibrogénicos, tales como factor de crecimiento transformante- $\beta$ (TGF- $\beta$ ) y trombina (Thompson 1998, Sitter y col 1999, Mutsaers 2002). En el peritoneo normal y en reparación, un diverso grupo de factores de crecimiento son la llave determinante en la composición de la MEC, y muchas de estas proteínas, tales como TGF- $\beta$, factor de crecimiento epitelial (EGF), factor de crecimiento tipo insulina (IGF), factor de crecimiento de fibroblastos (FGF) y factor de crecimiento vascular endotelial (VEGF), se encuentran implicadas en la formación de adherencias. La actividad coordinada de estos factores de crecimiento y moléculas bioactivas es responsable de la capacidad metabólica y proliferativa de las células fibroblásticas durante la formación de las adherencias y, por lo tanto, son un blanco atractivo para intervenciones terapéuticas (Cahill y col 2006, Boland y Weigel 2006). Holmdahl (1997) determinó en su estudio la expresión diferencial de PA y PAI tanto en mesotelio como submesotelio peritoneal. En el mesotelio normal, t-PA, u-PA y PAI-1 se encontraron presentes, a diferencia del submesotelio, donde sólo se encontró PAI-1 y u-PA pero no t-PA. En peritoneo inflamado, la expresión de t-PA en el mesotelio se encontró sustancialmente reducida, mientras que la expresión de PAI-1 en el submesotelio estuvo intensificada. La expresión de t-PA en el mesotelio pero no en el submesotelio sugiere que t-PA es el responsable de la depuración de fibrina en la cavidad peritoneal. Estudios que prueban el efecto terapéutico de t-PA en la formación de adherencias postoperatorias han demostrado que la administración de éste en la cavidad peritoneal durante el período postoperatorio disminuye la formación de adherencias (Boland y Weigel 2006). Igualmente, en estudios experimentales en ratas se ha descrito un aumento en la síntesis intraperitoneal de t-PA durante los días posteriores a la cirugía, lo cual fue interpretado como una reacción compensatoria para aumentar la deposición de fibrina (Polubinska y col 2006). Esto, debido a que en la cavidad abdominal t-PA sería responsable del 95\% de la conversión de plasminógeno (Holmdahl y col 1997); sin embargo, cirugías intraabdominales perturban el balance entre t-PA y PAI-1, lo que lleva a una disminución en la actividad fibrinolítica, a un aumento en el exudado fibrinoso y eventualmente a un aumento en la formación de adherencias (Scott-Coombes y col 1995).
La actividad fibrinolítica peritoneal y la formación de adherencias postoperatorias pueden estar reguladas, en parte, por la sustancia proinflamatoria peptídica P (SP) (Hökfelt y col 2001). Esta SP es un neuropéptido, neurotransmisor, neuromodulador y posee funciones endocrinas; además se le ha implicado en reacciones inflamatorias. SP es conocida por jugar un importante rol en el proceso de inflamación, proliferación y reparación de heridas. Los efectos conocidos de SP van desde favorecer la transcripción de ácido ribonucleico mensajero (mRNA) para favorecer la síntesis de citoquinas proinflamatorias hasta estimular la angiogénesis y proliferación de fibroblastos (Reed y col 2002). Las estructuras neuronales son la fuente primaria de SP, pero linfocitos (Lai y col 1998), monocitos, macrófagos (Ho y col 1997) y eosinófilos (Metwali y col 1994) han sido identificados como fuentes adicionales. La SP se encuentra en líquido peritoneal (Sanfilippo y col 1992) y neuronas sensitivas que contienen SP han sido encontradas en adherencias peritoneales (Sulaiman y col 2001). La multiplicidad de funciones y localizaciones celulares documentadas de SP sugiere un significativo rol en la formación de adherencias (Reed y col 2002). $\mathrm{El}$ hecho de que las adherencias se encuentren inervadas con neuronas sensitivas que contienen SP sugiere que son capaces de generar estímulos dolorosos y con esto favorecer el dolor visceral asociado a las adherencias (Becker y Stucchi 2004).

La distinción entre reparación peritoneal normal y formación de adherencias recae en el balance entre la deposición y degradación de fibrina. Se ha hipotetizado que la actividad fibrinolítica peritoneal juega un importante rol en la formación de adherencias. Si la fibrinólisis local es adecuada, las adherencias fibrinosas son lisadas llevando a una restauración normal del tejido. Sin embargo, si la fibrinólisis es insuficiente, la fibrina persistente se infiltra de fibroblastos y capilares llevando a adherencias fibrosas permanentes (Mueller 2002).

La reparación peritoneal difiere de la reparación de la piel. La reepitelización de la piel ocurre a través de proliferación de células epiteliales desde la periferia hacia el centro de la herida. En contraste, el peritoneo se mesoteliza, independiente del tamaño del daño, con nuevo mesotelio desarrollado a partir de islas de células mesoteliales, las cuales proliferan en capas celulares (Liakakos y col 2001). De manera interesante, cabe mencionar que, en el abdomen, la velocidad de reperitonealización es igual (7-10 días) independiente del tamaño inicial del daño; no se encuentra limitado el grado de migración de células desde la periferia (Boland y Weigel 2006). Leucocitos peritoneales, células mesoteliales y macrófagos son importantes componentes celulares en la reparación peritoneal. Este proceso está caracterizado por infiltración celular y una respuesta de crecimiento por parte de las células mesoteliales en el área dañada. En respuesta al daño inicial, las células residentes del peritoneo tales como macrófagos y células mesoteliales producen mediadores celulares, los cuales sirven para 
modular y ordenar la subsecuente respuesta de las otras células involucradas en la respuesta inflamatoria (Cheong y col 2001). Las células mesoteliales secretan interleuquín 1 (IL-1), 6 (IL-6), 8 (IL-8), factor de necrosis tumoral alfa (TNF- $\alpha$ ) y factor de crecimiento transformante (TGF)- $\beta$ al ser estimuladas in vitro, además de factor de crecimiento derivado de plaquetas (PDGF), factor de crecimiento de fibroblastos (FGF) y miembros de la familia de factores de crecimiento endotelial (EGF) regulando este proceso (Cheong y col 2001, Mutsaers 2002).

En gran parte del proceso de reparación de heridas (incluidas aquellas en la cavidad peritoneal), la primera fase iniciada por el daño del tejido lleva a la activación de la cascada de la coagulación. La respuesta vascular primaria al daño directo es la vasoconstricción, la cual es una respuesta local vasoactiva. El corto período de vasoconstricción es seguido por vasodilatación y pérdida de tono, permitiendo que factores sanguíneos entren en la herida. Las células invasoras son llevadas por gradiente de quimiotácticos y cambios bioquímicos en el ambiente local, mientras que el ambiente mismo es modificado por varios factores solubles circulantes que se encuentran disponibles en el sitio del daño (Boland y Weigel 2006). Las primeras células en aparecer en el peritoneo dañado son mayormente neutrófilos polimorfonucleares (PMN), los cuales persisten por 1-2 días. Esto es seguido por monocitos, los cuales se diferencian posteriormente en macrófagos que se adhieren a la superficie de la herida peritoneal (DiZerega 1990, DiZerega y Campeau 2001). Se ha demostrado también que el aumento de macrófagos disminuye marcadamente la formación de adherencias postoperatorias. Adicionalmente, se ha reportado que la inhibición en la capacidad de adherencia de los PMN resulta en un aumento en la formación de adherencias (Vural y col 1999).

Las plaquetas son un importante componente del exudado inflamatorio en el momento inicial del daño tisular. Poseen la habilidad de adherirse a los sitios de unión de la matriz extracelular (MEC). Las plaquetas provienen de megacariocitos de la médula ósea y contienen varios tipos de gránulos que liberan proteínas bioactivas en el sitio del daño. En la degranulación de las plaquetas, los gránulos alfa liberan factor de crecimiento derivado de plaquetas (PDGF) y TGF- $\beta$, mientras que los cuerpos densos liberan epinefrina y serotonina, contribuyendo a la producción de prostaglandinas y leucotrienos. En el peritoneo existen una serie de vías que llevan a deposición de fibrina posterior a la injuria; sin embargo, mucha de esta fibrina proviene de la deposición y degranulación de plaquetas. La fibrina depositada actúa como un puente o andamio provisional que facilita la conexión entre las superficies superpuestas. Se cree que esta acción de puente forma la arquitectura inicial de la subsecuente formación de adherencias (Boland y Weigel 2006). Para prevenir este proceso, la actividad fibrinolítica lisa y remueve los depósitos de fibrina intraperitoneal; además, es bien conocido que los macrófagos secretan activador de plasminógeno y al ser las células más comunes del líquido peritoneal exudativo, proveen la mayor fuente de esta enzima (Ar'Rajab y col 1995).

A partir del tercer día, las células mesoteliales comienzan a cubrir los macrófagos peritoneales de la superficie de la herida y éstos van quedando cada vez más profundos en la herida. En el día 4-7, las células predominantes en la superficie del peritoneo son células mesoteliales. Después del día 5 postquirúrgico, el mayor tipo celular en el líquido peritoneal son los macrófagos, pero comienzan a declinar en número (DiZerega 1990). En el día 5, las adherencias están pobladas mayormente por racimos de fibroblastos organizados con canales vasculares endoteliales lineales detectables y la matriz extracelular comienza a hacerse más densa y mejor organizada. Por lo tanto, al día 5 el rol local de las células inflamatorias en dirigir y/o modular la formación de adherencias disminuye y los fibroblastos son ahora el tipo celular primario. Estas células son similares a los miofibroblastos encontrados en heridas en otras áreas y expresan marcadores tales como actina muscular lisa alfa ( $\alpha$-SMA) (Boland y Weigel 2006). Luego, estas células mesoteliales proliferan a través de la base de la herida y forman múltiples islas de células. La confluencia de estas islas de células permite que grandes heridas reparen en el mismo tiempo que una de menor tamaño. Esta forma de reparación contrasta con la de la piel en donde la reparación comienza desde los bordes de la herida, es por esto que las grandes lesiones demoran más en sanar que las pequeñas (DiZerega 1990, DiZerega y Campeau 2001). Foley-Comer y col (2002) pudieron demostrar que las células mesoteliales de libre flotación son el origen del mesotelio en regeneración, requiriendo del reclutamiento de células inflamatorias hacia la superficie de la herida y la liberación de citoquinas mitogénicas que activen y estimulen la proliferación de células mesoteliales que rodean la herida. Estas células mesoteliales activadas rompen su contacto célula-célula y migran a la superficie de la herida.

\section{PREVENCIÓN Y TRATAMIENTO}

Acorde con Mueller (2002), el énfasis debe ser la prevención de la formación de adherencias, ya que el tratamiento después de formadas es complicado y costoso, asociado además a una alta morbilidad y mortalidad de los pacientes. La prevención en la formación de adherencias durante una cirugía exige reducir el trauma quirúrgico y evitar la contaminación de la cavidad abdominal con materiales extraños (Vrijland y col 2002). Sin embargo, el método más efectivo para prevenir las adherencias es una técnica quirúrgica excelente que minimice la inflamación peritoneal (Hay y col 2001). Esto coincide plenamente con Gorvy y col (2008), quienes señalan que el trauma quirúrgico es el estímulo más importante en la formación de adherencias, por lo tanto el manejo estricto de los principios de cirugía moderna de Halsted, incluyendo un manejo atraumático de los tejidos, hemostasis 
meticulosa, minimizar la contaminación del tejido por exposición a bacterias de la mucosa, minimizar la exposición a material extraño y disminuir el tiempo de la cirugía son esenciales para reducir la formación de adherencias postoperatorias (Mueller 2002). Estudios en ratones y humanos han demostrado que el talco de almidón usado en guantes quirúrgicos induce inflamación peritoneal y aumenta significativamente la formación de adherencias de una manera dependiente de la dosis (Chegini y Rong 1999, Sjösten y col 2004). Los objetivos primarios en la prevención de adherencias son los siguientes: a) minimizar la inflamación de la serosa, b) minimizar la producción de fibrina, c) estimular una motilidad intestinal adecuada y d) separar las superficies cubiertas por fibrina mecánicamente (Mueller y col 1998).

Las investigaciones acerca de la prevención y tratamiento de las adherencias postoperatorias se han focalizado en mejorar las técnicas quirúrgicas (Gorvy y col 2008), administración sistémica de fármacos antiinflamatorios no esteroidales (AINES) (White 1993), dimetil sulfóxido (DMSO) (Sullins y col 1991), antimicrobianos (White 1993), administración de heparina (Parker y col 1987), lavados peritoneales (Valdez y Wallace 1980, Hague y col 1998), administración intraperitoneal de soluciones de alto peso molecular y omentectomía (Baxter 1991, Murphy y col 2002), así como también la utilización de biomateriales naturales como peritoneo, omento, amnios, gelatina, colágeno y ácido hialurónico en ratas y conejos (Young y col 1991, Edwards y col 1997, Hellebrekers y col 2000, Matsuda y col 2002, Liu y col 2007). Sin embargo, los agentes terapéuticos que promueven la actividad fibrinolítica para prevenir la formación de adherencias deben ser usados durante la cirugía o posterior a ella; de acuerdo con Hellebrekers y col (2000), el tratamiento con estos promotores por 24 a $36 \mathrm{hrs}$ previno la formación de adherencias postquirúrgicas en un modelo murino.

Terapia analgésica. El grupo de analgésicos más utilizados para el tratamiento del dolor en patologías quirúrgicas y no quirúrgicas en equinos es el de los antiinflamatorios no esteroidales (AINES) (White 1999), sustancias diferentes a los esteroides que inhiben ciertas etapas y componentes de la cascada de la inflamación (Moses y Bertone 2002). De acuerdo a Hall y col (2001), son ampliamente usados en equinos para proveer analgesia en dolor agudo, debido a su acción antiinflamatoria, antiendotóxica y por además proveer analgesia en casos de dolor crónico. Los AINES difieren tremendamente en potencia y eficacia dependiendo del tipo de dolor e inflamación presentes, siendo lo más importante el realizar una adecuada selección clínica del fármaco a utilizar basándose en la sintomatología y objetivo clínico deseado (Clark y Clark 1999). Los AINES además pueden ser utilizados como agentes profilácticos en contra de la formación de adherencias por su habilidad de suprimir la respuesta inflamatoria fibroproliferativa, aumentar la capacidad fagocítica y la actividad fibrinolítica de macrófagos, así como reducir y mejorar la organización de fibrina (Semrad 1999). El resultado final depende de la severidad de la lesión, tiempo y cantidad de fármacos administrados y de cada paciente en forma individual (Sullins 1990).

El flunixin meglumine es, por lejos, el AINE más efectivo y más utilizado para tratar dolor visceral en caballos. Este fármaco ha demostrado aliviar cólicos experimentales dentro de los diez minutos posteriores a su administración endovenosa, proveyendo de una a ocho horas de analgesia (Morris 1988, Clark y Clark 1999). Sin embargo, estudios desarrollados en equinos han revelado que la administración de flunixin meglumine en dosis de $1,1 \mathrm{mg} / \mathrm{kg}$ retarda la recuperación de la función de la barrera intestinal del yeyuno isquémico y dañado (medido in vitro utilizando parámetros como resistencia eléctrica transmucosa y comparado con hallazgos en tejido no tratado) (Blikslager y col 1997, Campbell y Blikslager 2000, Tomlinson y col 2004). Asociado a esto, algunos AINES también pueden contribuir al daño isquémico durante la reperfusión tisular a través de la disminución del flujo sanguíneo local causado por la menor producción de PG (Tomlinson y Blikslager 2003).

Little y col (2007) reportan en su estudio de meloxicam, un AINE con mayor afinidad por ciclooxigenasa 2 (COX-2), que su administración no afecta la recuperación del yeyuno dañado e isquémico, lo que, de acuerdo a los autores, podría deberse a que este fármaco, al no inhibir masivamente la enzima ciclooxigenasa 1 (COX-1), permite su suficiente actividad asociada a procesos de reparación, mediada por prostaglandinas (PG). Esta reparación de la función de barrera intestinal, inhibiendo los efectos perjudiciales de las PG, elaboradas por COX-2, además de los signos clínicos de endotoxemia y dolor, hace que su uso sea considerado por los autores como una buena alternativa al flunixin meglumine en equinos ya que provee un adecuado nivel de analgesia, efectos benéficos sobre variables clínicas, además de permitir la recuperación intestinal.

Lavados peritoneales. El peritoneo, especialmente su porción visceral, es una barrera semipermeable con difusión bidireccional de agua y solutos. Las soluciones administradas en la cavidad peritoneal rápidamente se equilibran con el plasma. Consecuentemente, la administración de fármacos intraperitoneales tiene una absorción similar a la administración intramuscular (Bowman 1990).

Con objeto de reducir el riesgo de peritonitis bacteriana, los lavados peritoneales o lavados locales de una porción intervenida quirúrgicamente son realizados posterior a intervención quirúrgica del tracto gastrointestinal (Schneider y col 1988). Los beneficios del lavado peritoneal se pueden atribuir a eliminación de sangre acumulada en la cavidad peritoneal, reducción del número de bacterias, remoción de toxinas y enzimas bacterianas en un área de gran absorción, remoción de materiales extraños (Valdez y Wallace 1980), además de la remoción física de fibrina desde las superficies 
serosas, separación de las asas intestinales y remoción de mediadores inflamatorios (Hague y col 1998).

Los lavados intraabdominales postquirúrgicos han demostrado minimizar la incidencia de adherencias en abrasión de serosa experimental en caballos. La técnica descrita consiste en la infusión de aproximadamente $10 \mathrm{~L}$ de suero Ringer lactato tibio en el abdomen a través de un catéter fenestrado $32 \mathrm{~F}$ puesto en el abdomen ventral derecho previo al acto quirúrgico. El lavado se realiza a las 12, 24 y 36 horas posteriores a la cirugía y luego el catéter es removido (Hague y col 1998).

Los anticoagulantes, en especial heparina, han sido los agentes más investigados para la prevención de adherencias, administrados tanto por vía peritoneal como sistémica (Gupta y Jain 1985, Türkçapar y col 1995, Arikan y col 2005). La heparina es un proteoglicano natural y ha sido descrito como un reductor en la formación de adherencias en modelos de isquemia-reperfusión en ponies (Parker y col 1987). La heparina actúa como un cofactor de antitrombina III para aumentar el grado de antitrombina II, inactivando el factor de coagulación serina proteasa. El resultado es la disminución en la producción de trombina, la cual es la responsable de la conversión de fibrinógeno en fibrina y finalmente de las adherencias fibrosas. Es por esto que la heparina realza la fibrinólisis a través del estímulo de la actividad del PA (Eggleston y Mueller 2003). Igualmente, el efecto de disminución en la formación de adherencias de la heparina de bajo peso molecular puede explicarse por los diferentes mecanismos de acción de la molécula de heparina, la cual al formar el complejo con antitrombina III in vivo previene la formación de trombina, además de aumentar la degradación de trombina (Rosenberg y Damus 1973).

Además la heparina posiblemente estimula la secreción de activador de plasminógeno (PA) por parte de macrófagos (Markwardt y Klocking 1977) y también estimula directamente la actividad de PA, por lo tanto, aumenta la acción de plasminógeno (Orita y col 1986). De acuerdo a esto, la deposición de fibrina durante la segunda fase de la formación de adherencias disminuye, lo que resulta en una menor formación de adherencias (Arikan y col 2005). Sin embargo, Sullins y col (2004) establecen en su estudio en potrillos que el rol de la heparina en la prevención de inflamación serosa inducida por isquemia es limitado, ya que los segmentos de intestino delgado tratados con heparina desarrollaron fibrosis aumentada y el mesotelio no regeneró, lo que indicaría que la respuesta inflamatoria no mejora o que el exudado de fibrina aumentó en los segmentos experimentales, los cuales después se organizaron en tejido fibroso, el cual obstaculiza la migración de nuevas células mesoteliales. De igual forma, la heparina ha demostrado ser útil en presencia de sepsis por dos razones, la primera es que hay una directa actividad antibacteriana in vitro de mecanismo desconocido (Rosett y Hodges 1980) y la segunda es que disminuciones en la formación de fibrina resultan en menor formación de abscesos y adherencias, previniendo el secuestro y aumento de eliminación de microorganismos en perros y ratas (Hau y Simmons 1976, Hau y col 1979, Vela y col 1999). Las dosis recomendadas en equinos y la(s) vía(s) de administración continúan siendo controversiales. Dosificaciones sistémicas de 20 a $100 \mathrm{UI} / \mathrm{kg}$ cada 6 a 12 horas, por 48 a 72 horas en el período postoperatorio, han sido usadas incluso para lavados peritoneales (Mueller 2002).

Ya en 1940, Lehman y Boys detallan que la instilación de heparina en la cavidad peritoneal en perros y conejos era efectiva en la prevención de formación y reformación de adherencias. Sin embargo, Bloor y col (1947) establecen en su estudio que al ser administrada en dosis elevadas no previene la formación o reformación de adherencias intraperitoneales o la deposición de fibrina en la superficie de apéndices en conejos. En modelos de peritonitis en diversos roedores, pequeñas dosis de heparina han demostrado disminuir la incidencia en la formación de adherencias, aumentar la supervivencia y la tasa de eliminación de fibrinógeno intraabdominal (O’Leary y col 1988). Bahadir y col (2007) concluyen de su estudio en ratones que el uso de heparina en dosis bajas contribuye a reducir la incidencia de adherencias; sin embargo, señalan que es necesario realizar más estudios para conocer la dosis óptima y evitar así disminuir la severidad de las adherencias, además de hemorragias abdominales. En equinos, ante el riesgo de formación de adherencias, Mueller (2002) señala que la administración de 30.000 UI de heparina diluida en 4 litros de suero Ringer lactato en el abdomen antes del cierre y manteniendo al caballo con $40 \mathrm{UI} / \mathrm{kg}$ de heparina sulfato, endovenosa, cada 6 horas por 48 a 72 horas postoperatorio sería de utilidad. La administración sistémica de heparina en caballos produce además una disminución transitoria del VGA, alcanzando hasta 50\% después de 3 a 4 días de terapia. Se cree que esta disminución ocurre por aglutinación eritrocitaria y no por hemorragia o hemólisis (Mahaffey y Moore 1986). El VGA vuelve a valores normales dentro de 4 días de finalizada la terapia con heparina (Mueller 2002).

Posterior a una laparotomía, alrededor del $95 \%$ de los pacientes humanos desarrollan adherencias. Para prevenir esta formación se han investigado los lavados peritoneales y muchas diferentes soluciones han sido propuestas (Sortini y col 2006). Los lavados intraabdominales intraoperatorios se abocan a prevenir la desecación de las superficies serosas, minimizar el trauma seroso durante la manipulación intestinal y remover la sangre, fibrina peritoneal y mediadores inflamatorios (Hague y col 1998). Aparentemente el lavado postquirúrgico crea un efecto de hidroflotación, el cual separa la superficie de la serosa intestinal y además remueve fibrina peritoneal y mediadores inflamatorios (Mueller 2002). Hague y col (1998) concluyen que el lavado peritoneal reduce la frecuencia de adherencias intraabdominales. Sin embargo, Johns (2001) señala que en humanos, a pesar del volumen aplicado, la capacidad de absorción del peritoneo asegura que este fluido es 
reabsorbido al sistema vascular dentro de 24-48 horas, tiempo muy corto como para influir en la formación de adherencias. No existen ensayos clínicos controlados que demuestren que la hidroflotación tenga algún efecto en la formación de adherencias postoperatorias en equinos.

Igualmente, otras combinaciones han sido utilizadas en forma de lavado peritoneal. Un estudio realizado por Wang y col (2003) en perros concluye que el uso de una solución combinada de alantoína, metronidazol y dexametasona (AMD) sería de utilidad por su efecto antiinflamatorio, antibacteriano y antiexudativo, impidiendo que el exudado rico en fibrina quede en la cavidad abdominal, y además aumentaría la actividad del PA de tejido endogenético, lo que prevendría las adherencias intraabdominales postoperatorias. De acuerdo al estudio piloto, la proporción más adecuada de estos fármacos fue 50:32:1, la cual además demostró ser la combinación más efectiva, mientras que la toxicidad no aumentó. Hague y col (1998) concluyen en su estudio que los lavados para remover sangre peritoneal y fibrina en el período inmediato postcirugía son beneficiosos en la prevención de adherencias, siendo mejores que los intraoperatorios ya que permiten la remoción de fibrina que se forma después de la cirugía.

Igualmente, se ha documentado que el uso de soluciones protectoras tisulares aplicadas al tejido antes de la manipulación quirúrgica y durante la cirugía protege las superficies mesoteliales directamente y previene o reduce el tejido dañado durante el procedimiento quirúrgico, el cual puede llevar a la formación de adherencias (Murphy y col 2002). Las soluciones o sustancias que previenen las adherencias se caracterizan por inhibir la adhesiogénesis sin restringir la reparación de la herida, son eficaces aún en presencia de sangre u otros fluidos corporales, tienen propiedades antiinflamatorias, ausencia de factores inmunológicos, biodegradabilidad, seguridad de permanecer en el lugar después de la aplicación, facilidad de manejo y efecto inmediato (Risberg 1997).

La administración intraperitoneal de soluciones de carboximetilcelulosa sódica (CMC) al 1\%, un polisacárido sustituido, ha sido usada con éxito en modelos experimentales para prevenir las adherencias en animales de laboratorio, ovejas y ponies (Hay y col 2001), siendo los volúmenes recomendados entre 1 y $7 \mathrm{~mL} / \mathrm{kg}$ introducidos dentro del abdomen antes de la manipulación intestinal; sin embargo, algunos cirujanos prefieren depositar una solución de 4-5 $\mathrm{mL} / \mathrm{kg}$ de CMC al $1 \%$ dentro del abdomen justo antes de terminar la sutura de la línea alba (Smith y col 2005). Sullins y col (2004) describen que el uso de una solución de CMC al $3 \%$ en potrillos aumentó la fibrosis y disminuyó la regeneración mesotelial, fenómeno relacionado a la irritación de las superficies. La carboximetilcelulosa (CMC) se encuentra actualmente disponible en tres diferentes gamas de pesos moleculares: baja ( $90 \mathrm{kd})$, media (250 a $350 \mathrm{kd})$ y alta (700 a $1000 \mathrm{kd})$. En estudios en equinos han sido utilizadas soluciones de CMC con moléculas de peso medio como barreras postoperatorias para prevenir adherencias intraabdominales. Aunque la CMC es biocompatible, cambios leves y transitorios se han observado en variables hematológicas y bioquímicas al usarla intraabdominalmente en caballos (Murphy y col 2002). Los efectos benéficos de CMC derivan de un efecto de hidroflotación, el cual mecánicamente previene la aposición de las superficies serosas o peritoneales, previniendo así la formación de adherencias (Mueller y col 1998).

Lopes y col (1999) observaron que posterior a infusiones con CMC al $1 \%$ existe un aumento en la densidad y proteínas totales; adicionalmente encontraron un incremento en el conteo de leucocitos, así como también un aumento relativo de neutrófilos, por lo cual concluyen que la CMC causó una respuesta inflamatoria más intensa y con un curso mayor en la cavidad peritoneal y que su excreción ocurre por fagocitosis. Hay y col (2001) reportan que la CMC disminuyó la incidencia de adherencias en respuesta a la abrasión de serosas y resección yeyunal y anastomosis. Un litro de CMC al $1 \%$ es suficiente para cubrir todo el yeyuno e íleon, lo que lleva a la lubricación del intestino y guantes de los cirujanos, lo que subjetivamente reduce la fricción durante la manipulación intestinal. Un segundo litro de $\mathrm{CMC}$ al $1 \%$ es aplicado después de la manipulación, llevando a la acumulación de CMC en el lugar de la cirugía. Sin embargo, grandes volúmenes de CMC (2-4 litros) deben ser usados para alcanzar el efecto de hidroflotación en el abdomen de los equinos. Igualmente, se ha establecido que la absorción sistémica después de la administración intraperitoneal de grandes volúmenes de CMC en caballos resulta en pirexia, depresión y anorexia postoperatoria (Mueller y col 2000a). En este sentido, Hay y col (2001) determinaron en ponies y caballos que el uso de $7 \mathrm{~mL} / \mathrm{kg}$ de SCMC al $1 \%$ no genera complicaciones como las descritas anteriormente. De la misma forma, en su estudio el uso de 4-6 mL/kg de CMC al $1 \%$ fue efectivo para prevenir las adherencias y no se observó este tipo de efectos secundarios. Igualmente, el hialuronato de sodio, un polímero hidrofílico natural y excelente lubricante de tejidos, ha demostrado ser efectivo en reducir las adherencias postquirúrgicas después de cirugías abdominales, pericárdicas y ortopédicas, previniendo la formación de adherencias primariamente a través de la formación de una barrera lubricante protectora en la superficie serosa intestinal, parecida a CMC, previniendo el trauma abrasivo por manipulación y desecación y preservando la integridad del mesotelio. Igualmente, concentraciones de $0,4 \%$ de hialuronato de sodio han demostrado inhibir la formación de adherencias en ratas (Burns y col 1995, Peck y col 1995), siendo esta solución reabsorbida de la cavidad peritoneal y excretada dentro de los cinco días de administrada en cerdos (Kramer y col 2002).

Barreras físicas. Un acercamiento a la prevención de las adherencias intraabdominales en equinos es colocar un material absorbible biocompatible en el abdomen, el cual sirve como barrera física durante el período postoperatorio 
cuando se forman las adherencias (Avital y col 2005). Recientemente, una membrana bioabsorbible compuesta de la combinación de hialuronato (HA) y CMC se ha desarrollado para reducir la formación de adherencias después de cirugías en humanos. Esta membrana translúcida y flexible ha sido evaluada clínicamente en humanos y equinos y es utilizada en la superficie serosa del intestino o peritoneo, formando una barrera protectiva temporal contra la formación de adherencias serosa-serosa o serosa-peritoneo durante el período postoperatorio temprano (Mueller y col 2000 ${ }^{b}$, Cohen y col 2005). La combinación de HA y $\mathrm{CMC}$ produce un compuesto con una permanencia in vivo mayor comparado con HA o CMC solos. La membrana se hidrata a un gel aproximadamente 24 a 48 horas después de su aplicación, pero permanece en el sitio de la aplicación por más de siete días, lo que realza su habilidad de reducir la formación de adherencias (Mueller y col $2000^{a}$ ) en incidencia, extensión y severidad (Vrijland y col 2002). Mueller y col (1998) establecieron que el uso de la membrana bioabsorbible HA previene la formación de adherencias intraabdominales inducidas experimentalmente en todos los caballos tratados, por lo cual se concluye que la membrana HA previene la formación de adherencias por un mecanismo similar al de CMC, que es separar las superficies serosas durante el período postoperatorio temprano de la reparación. Adicionalmente Mueller y col $\left(2000^{b}\right)$ describen que mediante evaluación microscópica de los sitios de anastomosis de todos los grupos se pudo observar la evidencia de tejido de granulación con invasión de macrófagos y proliferación fibroblástica, típico de la reparación normal de una herida. Sin embargo, la acumulación de fibrina en la superficie serosa del sitio de la anastomosis, en los grupos tratados con membrana de CMC y HA, fue significativamente menor que los caballos controles. Bajo condiciones normales, la fibrina es disuelta por el sistema fibrinolítico y las adherencias son resueltas antes de que haya una maduración fibrosa. Estos mismos autores señalan que esta disminución en la deposición de fibrina en el sitio de la anastomosis en los grupos de caballos tratados con membranas de CMC y HA no comprometió la fuerza o reparación del intestino delgado en el modelo experimental utilizado. Estos resultados concuerdan además con Tarhan y col (2005) quienes al ocupar una membrana de HA y CMC redujeron la incidencia y severidad de las adherencias abdominales en ratas.

Aunque t-PA es el activador de plasminógeno que es responsable del $95 \%$ de la actividad, los resultados indican que el efecto de prevenir adherencias de la membrana de HA y CMC no se encuentra relacionado con t-PA. Debido a esto, las propiedades físicas (efecto barrera, hidroflotación y siliconización) de la membrana pueden ser responsables primariamente de la prevención de adherencias. Tsai y col (2005) concluyen de su estudio de membranas de colágeno-hialuronato que éstas son resistentes a la digestión de hialuronidasa y no demostraron ser citotóxicas a fibroblastos L929. Al ser implantadas en ratas por más de cuatro semanas, previnieron la formación de adherencias, asociándose sólo a una suave reacción tisular. Por lo cual los resultados de ese estudio sugieren que estas membranas pueden ser una buena barrera mecánica para prevenir las adherencias intraperitoneales postoperatorias.

Aunque no utilizado en equinos, el quitosán es otro tipo de membrana utilizado para la prevención de adherencias. Éste es un derivado de la quitina obtenida después de deacetilación, siendo la quitina el principal ingrediente del caparazón de los artrópodos (tales como camarones, cangrejos, insectos, etc.), el cual es una fuente renovable natural y de gran cantidad. Al ser el quitosán inocuo, biodegradable y con una biocompatibilidad ideal, ha sido ocupado para desarrollar biomateriales. La actividad biológica del quitosán incluye: inhibición del crecimiento de bacterias, actividad antineoplásica, aumento inmunológico, actividad anticoagulante, promoción de la reparación tisular y hemostasis (Zhang y col 2006). Sin embargo, Zhang y col (2006) concluyen en su estudio que las membranas de quitosán pueden no prevenir las adherencias por su baja velocidad de degradación in vivo; además las membranas mezcladas con gelatina pueden incluso exacerbar las adherencias peritoneales. Igualmente, señalan que el gel de quitosán tiene un buen efecto en la prevención de adherencias peritoneales causadas por isquemia, pero no un efecto evidente en adherencias causadas por polvo de talco. Otros autores (Kennedy y col 1996, Costain y col 1997) han probado el uso de N,O-carboximetilquitosán (NOCC); esta molécula es parecida al ácido hialurónico y la $\mathrm{CMC}$, los cuales han demostrado ser beneficiosos en la reducción de adherencias. Una serie de estudios se han realizado en distintos tipos de cirugía. Sin embargo, Diamond y col (2003) determinaron la eficacia promisoria en modelos animales de NOCC al reducir adherencias postoperatorias, demostrando su habilidad de disminuir la ocurrencia, extensión y severidad en humanos, por lo cual ofrecería grandes beneficios en la reducción de la formación de adherencias.

Otro material utilizado como membrana es el ácido poliláctico, el cual está compuesto de un copolímero de dos formas de ácido láctico ( $\mathrm{L}_{\mathrm{L}}$-lactida $\mathrm{y}_{\mathrm{D}, \mathrm{L}}$-lactida). Este polímero es degradado en el cuerpo por hidrólisis seguido de metabolismo hepático. Es un material flexible que no se dobla o arruga fácilmente y puede ser manejado fácilmente con guantes. Al respecto, estos autores señalan que el uso experimental de esta membrana en ratas estuvo asociado a una reducción del $42,1 \%$ de las adherencias intraabdominales postoperatorias así como también su severidad, haciendo notar que estos resultados se alcanzaron en un modelo que desarrolla un ciento por ciento de adherencias en las ratas no tratadas (Avital y col 2005).

Schneider y col (2006) establecen el uso de una esponja de colágeno derivada de tendones equinos (TachoComb H), un agente hemostático, el cual está cubierto de una capa de factores de coagulación tales como fibrinógeno 
(humano) y trombina (humana) y un inhibidor de fibrinólisis aprotinina (bovino). Estos autores describen una disminución significativa en la formación de adherencias en el grupo tratado comparado con el grupo control. Sin embargo, señalan que es necesario realizar más investigaciones comparando este producto con otras barreras mecánicas.

Drenajes. Los drenajes abdominales han sido usados para muchas patologías, incluyendo peritonitis, abscesos intraabdominales, hemorragias y filtraciones de anastomosis. Igualmente son usados postoperatoriamente para prevenir la formación de adherencias o la acumulación de sustancias irritantes como sangre, bilis o enzimas pancreáticas (Nieto y col 2003). Los drenajes son implantes quirúrgicos, los cuales proveen y mantienen un canal de salida con el propósito de remover fluidos o gases desde una herida o cavidad corporal (Williams y col 1992). Celsius fue la primera persona en utilizar drenajes en el abdomen para remover fluido ascítico. Galen en el siglo II y Avicena en el XI aplicaron este tratamiento para ascitis; después de este tiempo no existen registros de su uso, hasta que Chauliac aparentemente lo redescubrió en el siglo XIV. Paré y Ryff, en el XVI, Scultetus en el XVII y Heister en el siglo XVIII usaron tubos metálicos ensanchados como drenajes de fluido intraabdominal (Jennings 1937).

Los drenajes pueden ser pasivos o activos. Los pasivos funcionan por desbordamiento, gravedad o acción capilar y los activos por aplicación de una fuente externa de vacío al drenaje (Arighi 1992). El uso de una fuente de succión externa para crear presión negativa tiene ventajas sobre los drenajes pasivos (Stone 1992). Los drenajes pasivos más comúnmente usados son los drenajes de Penrose, gomas de látex dental y drenajes corrugados (Williams y col 1992). Los activos promueven el drenaje peritoneal, están asociados a una reducción en la incidencia de infecciones y complicaciones relacionadas a los drenajes y el volumen de egreso puede ser medido. Cuando se usan los drenajes pasivos en la cavidad abdominal, se recomienda proteger el extremo del drenaje para prevenir infecciones ascendentes (Stone 1992). De acuerdo a Eggleston y Mueller (2003) y Nieto y col (2003) las complicaciones asociadas a drenajes abdominales y lavados en otras especies incluyen hipoproteinemia, pérdida de fluidos y electrolitos, perforación de vísceras, infecciones ascendentes, herniación del omento o intestino a través de la salida del drenaje y obstrucción del drenaje, además de edema ventral localizado en el sitio donde se encuentra el catéter. En caballos, drenajes pasivos y lavados han sido usados en el tratamiento de peritonitis sépticas y experimentalmente para minimizar la formación de adherencias. Nieto y col (2003) consideran que debido a la ausencia de complicaciones severas y a la aparente mejora clínica, la utilización de sistemas de drenajes activos puede ser una terapia alternativa adecuada para el tratamiento y prevención de peritonitis como también para la disminución en la presentación de adherencias postquirúrgicas en equinos.

Manejo quirúrgico. Otro tipo de tratamiento recomendado para las adherencias abdominales involucra repetir la celiotomía con objeto de eliminar las adherencias formadas. Desafortunadamente, este es un procedimiento invasivo, el cual ha resultado en la formación de futuras adherencias en humanos y animales de laboratorio (Lansdowne y col 2004). La relaparotomía en equinos (previo al alta desde el hospital veterinario) es altamente aceptada como una opción de tratamiento en el manejo de cólico postquirúrgico (Ducharme 2002), aunque de acuerdo a Hay y Mueller (1998) en equinos la ruptura de las adherencias durante una cirugía generalmente lleva a que se formen nuevamente debido a la naturaleza altamente irrigada de la zona afectada y a la severidad asociada del daño de la adherencia original. Además, la repetición de una celiotomía para corregir problemas asociados a las adherencias abdominales o el manejo de episodios recurrentes de cólico atribuibles a las adherencias son por lo general no factibles económicamente (Fubini 1990, Sullins 1990, Baxter 1992), por lo cual los propietarios frecuentemente eligen eutanasiar al caballo (Bouré y col 2002).

La laparoscopia diagnóstica es usualmente usada para identificar patologías intraabdominales específicas como el caso de dolor abdominal y pélvico crónico (Shayani y col 2002). Exitosas adhesiólisis laparoscópicas han sido descritas en equinos; las ventajas reportadas de esta técnica incluyen excelente observación de las adherencias abdominales y mínimo trauma del peritoneo parietal y visceral comparado con laparotomías (Bleyaert y Brown 1997, Bouré y col 1998). Lansdowne y col (2004) reportan en su estudio en potrillos que la instilación de hialuronato férrico $0,5 \%$ en gel posterior a la disección laparoscópica de adherencias es más efectiva que la disección laparoscópica sola, además de ser una técnica segura y efectiva de realizar en potrillos. Lansdowne y col (2004) reportan en su estudio laparoscópico en ponies realizado siete días después de la celiotomía inicial que, independiente del uso de la misma técnica quirúrgica para inducir las adherencias y el mismo equipo quirúrgico, ocurrió una reformación de adherencias. Extensivos estudios se han desarrollado para determinar el mejor tratamiento de adherencias abdominales postquirúrgicas en humanos (Caspi y Halperin 1981, François y col 1994). Sobre el $80 \%$ de pacientes humanos con dolor abdominal crónico son aliviados o presentan mejorías clínicas después de adhesiólisis laparoscópica (Borellino y col 1998). En medicina humana, el tiempo ideal para realizar adhesiólisis laparoscópica no ha sido aún determinado, pero en general es aceptado que este procedimiento debe ser realizado después de la reparación de la serosa y antes de que se desarrollen las adherencias fibrosas (Jansen 1988).

En equinos, la realización de omentectomía es aún controversial (Hay y Mueller 1998). Kuebelbeck y col (1998) 
encontraron en su estudio que el omento frecuentemente se encuentra relacionado a las adherencias causando dolor abdominal por la formación de éstas en el intestino o pared abdominal que llevan a obstrucción o estrangulación, además de que la omentectomía reduce el grado de formación de adherencias postoperatorias, siendo un procedimiento seguro, el cual debe ser considerado profilácticamente para atenuar la formación de adherencias después de cirugías abdominales en caballos. En contraste, Mueller (2002) indica que a pesar de que las adherencias omentales pueden causar signos de dolor abdominal a través de la creación de una tensión anormal en el mesenterio, o como foco de obstrucción o estrangulación intestinal, se ha descrito que proveen un aporte vascular al tejido potencialmente isquémico, de tal modo, facilita la reparación y prevendría la formación de adherencias.

\section{RESUMEN}

A pesar del gran número de investigaciones realizadas tanto en medicina humana como en medicina veterinaria, las adherencias intraabdominales continúan siendo una complicación para los cirujanos en la actualidad. El desarrollo de adherencias intraabdominales es un proceso dinámico y complejo que involucra una serie de eventos que comienzan con un proceso inflamatorio y daño tisular, seguido de desbalances en los procesos de fibrinogénesis y fibrinólisis, terminando con la conversión de fibrina a tejido fibroso. En cirugías de intestino delgado en equinos, la incidencia de adherencias va de 14 a $22 \%$, siendo la causa más común de dolor abdominal recurrente y la segunda causa de celiotomías repetidas. Sin embargo, al incluir todas las causas de cirugías abdominales, en esta especie la incidencia de adherencias es de aproximadamente un 5\%. El mayor conocimiento del mecanismo celular de la formación y reformación de adherencias debe llevar a reducir su incidencia. Actualmente, existen una serie de métodos de prevención y tratamientos destinados a disminuir o evitar la aparición de adherencias intraabdominales. El objetivo de esta revisión bibliográfica fue el de recopilar la mayor información disponible e investigaciones que expliquen de mejor manera la fisiopatología, prevención y tratamiento de la formación de adherencias intraabdominales.

\section{REFERENCIAS}

Arighi M. 1992. Drains, and external coaptation devices. In: Auer JA (ed). Equine Surgery. WB Saunders, Philadelphia, USA, Pp 159-176.

Arikan S, G Adas, G Barut, A Savas, A Kocakusak, H Uzun, O Kemik, Y Daduk, S Aydin, S Purisa. 2005. An evaluation of low molecular weight heparin and hyperbaric oxygen treatment in the prevention of intraabdominal adhesions and wound healing. Am J Surg 189, 155-160.

Ar'Rajab A, I Dawidson, J Sentementes, P Sises, R Harris, W Mileski. 1995. Enhancement of peritoneal macrophages reduces postoperative peritoneal adhesion formation. J Surg Res 58, 307-312.

Avital S, TJ Bollinger, JD Wilkinson, F Marchetti, MD Hellinger, LR Sands. 2005. Preventing intraabdominal adhesions with polylactic acid film: an animal study. Dis Colon Rectum 48, 153-157.

Bahadir I, M Oncel, M Kement, Y Sahip. 2007. Intraabdominal use of taurolidine or heparin as alternative products to an antiadhesive barrier (Seprafilm $®$ ) in adhesion prevention: An experimental study on mice. Dis Colon Rectum 50, 2209-2214.

Baxter GM, TE Broome, JN Moore. 1989. Abdominal adhesions after small intestinal surgery in the horse. Vet Surg 18, 409-414.

Baxter GM. 1991. Intraabdominal adhesions in horses. Compend Contin Educ Pract Vet 13, 1587-1597.
Baxter GM. 1992. Recognizing and managing the postoperative complications of equine abdominal surgery. Vet Med 87, 11131120.

Becker JM, AF Stucchi. 2004. Intraabdominal adhesion prevention: are we getting any closer? Ann Surg 240, 202-204.

Bleyaert HF, MP Brown. 1997. Laparoscopic adhesiolysis in a horse. Vet Surg 26, 492-496.

Blikslager AT, MC Roberts, JM Rhoads, RA Argenzio. 1997. Prostaglandins $\mathrm{I} 2$ and $\mathrm{E} 2$ have a synergistic role in rescuing epithelial barrier function in porcine ileum. J Clin Invest 100, 1928-1933.

Bloor BM, H Dortch, TH Lewis, RF Kibler, KS Shepard. 1947. The effect of heparin upon intraabdominal adhesions in rabbits. Ann Surg 126, 324-331.

Boland GM, RJ Weigel. 2006. Formation and prevention of postoperative abdominal adhesions. J Surg Res 132, 3-12.

Borellino G, G De Manzoni, F Ricci. 1998. Detection of abdominal adhesions in laparoscopic surgery. A controlled study of 130 cases. Surg Laparosc Endosc 8, 273-276.

Bouré LP, M Marcoux, JP Lavoie, S Laverty. 1998. Use of laparoscopic equipment to divide abdominal adhesions in a filly. $J$ Am Vet Med Assoc 212, 845-847.

Bouré LP, SG Pearce, CL Kerr, JL Lansdowne, CA Martin, AL Hathway, JL Caswell. 2002. Evaluation of laparoscopic adhesiolysis for the treatment of experimentally induced adhesions in pony foals. $\mathrm{Am}$ J Vet Res 63, 289-294.

Bowman KF. 1990. Peritonitis and peritoneal drainage. In: White NA, Moore JN (eds). Current Practice of Equine Surgery. JB Lippincott, Philadelphia, USA, Pp 377-382.

Browning A. 2005. Diagnosis and management of peritonitis in horses. In Practice 27, 70-75.

Burns J, K Skinner, J Colt, A Sheidlin, R Bronson, Y Yaacobi, EP Goldberg. 1995. Prevention of tissue injury and postsurgical adhesions by precoating tissues with hyaluronic acid solutions. $J$ Surg Res 59, 644-652.

Cable CS, SC Fubini, HN Erb, JE Hakes. 1997. Abdominal surgery in foals: a review of 119 cases (1977-1994). Equine Vet J 29, 252-254.

Cahill RA, JH Wang, S Soohkai, HP Redmond. 2006. Mast cells facilitate local VEGF release as an early event in the pathogenesis of postoperative peritoneal adhesions. Surgery 140, 108-112.

Campbell NB, AT Blikslager. 2000. The role of cyclooxygenase inhibitors in the repair of ischaemic-injured jejunal mucosa in the horse. Equine Vet J Suppl 32, 59-64

Caspi E, Y Halperin. 1981. Surgical management of periadnexal adhesions. Int J Fertil 26, 49-52.

Chegini N, H Rong. 1999. Postoperative exposure to glove powders modulates production of peritoneal eicosanoids during peritoneal wound healing. Eur J Surg 165, 698-704.

Cheong YC, SM Laird, JB Shelton, WL Ledger, ID Cooke. 2001. Peritoneal healing and adhesion formation/reformation. Hum Reprod Update 7, 556-566.

Clark JO, TP Clark. 1999. Analgesia. Vet Clin Equine 15, 705-723.

Cohen Z, AJ Senagore, MT Dayton, MJ Koruda, DE Beck, BG Wolff, PR Fleshner, RC Thirlby, KA Ludwig, SW Larach, EG Weiss, JJ Bauer, L Holmdahl. 2005. Prevention of postoperative abdominal adhesions by a novel, glycerol/sodium hyaluronate/ carboxymethylcellulose-based bioresorbable membrane: a prospective, randomized, evaluator-blinded multicenter study. Dis Colon Rectum 48, 1130-1139.

Collatos C, MH Barton, R Schleef, KW Prasse, JN Moore. 1994. Regulation of equine fibrinolysis in blood and peritoneal fluid based on a study of colic cases and induced endotoxaemia. Equine Vet $J$ 26, 474-481.

Costain DJ, R Kennedy, C Ciona, VC McAlister, TD Lee. 1997. Prevention of postsurgical adhesions with N,O-carboxymethyl chitosan: examination of the most efficacious preparation and the effect of N,O-carboxymethyl chitosan on postsurgical healing. Surgery 121, 314-319. 
Diamond MP, A Luciano, DA Johns, R Dunn, PYoung, E Bieber. 2003. Reduction of postoperative adhesions by N,O-carboxymethylchitosan: a pilot study. Fertil Steril 80, 631-636.

Didio LJA. 1994. Esplacnología. En: Sisson S, Grossman JD (eds). Anatomía de los animales domésticos. Salvat, México, Pp 96-117.

Di Filippo C, A Falsetto, V De Pascale, E Tufariello, D De Lucia, F Rossi, M D'Amico, A Cennamo. 2006. Plasma levels of t-PA and PAI-1 correlate with the formation of experimental post-surgical peritoneal adhesions. Mediators Inflamm 2006, 1-4.

DiZerega GS. 1990. The peritoneum and its response to surgical injury. Prog Clin Biol Res 358, 1-11.

DiZerega GS, JD Campeau. 2001. Peritoneal repair and post-surgical adhesion formation. Hum Reprod Update 7, 547-555.

Ducharme NG. 2002. Repeat laparotomy. In: Mair TS, Divers T, Ducharme NG (eds). Manual of Equine Gastroenterology. WB Saunders, London, UK, Pp 184-187.

Duron JJ. 2007. Postoperative intraperitoneal adhesion pathophysiology. Colorectal Disease 9, 14-24.

Edwards, GA, V Glattauer, TJ Nash, JF White, KA Brock, JA Werkmeister, JA Ramshaw. 1997. In vivo evaluation of a collagenous membrane as an absorbable adhesion barrier. J Biome Mater Res 34, 291-297.

Eggleston RB, E Mueller. 2003. Prevention and treatment of gastrointestinal adhesions. Vet Clin North Am Equine Pract 13, 741-763.

Ellies H. 1962. The aetiology of postoperative abdominal adhesions. An experimental study. Br J Surg 50, 10-16.

Foley-Comer AJ, SE Herrick, T Al-Mishlab, CM Prêle, GJ Laurent, SE Mutsaers. 2002. Evidence for incorporation of free-floating mesothelial cells as a mechanism of serosal healing. J Cell Sci 115, 1383-1389.

Francois Y, P Mouret, K Tomaoglu, J Vignal. 1994. Postoperative adhesive peritoneal disease. Laparoscopic treatment. Surg Endosc 8, 781-783.

Freeman DE, P Hammock, GJ Baker, JH Foreman, DJ Schaeffer, RA Richter, O Inove, JH Magid. 2000. Short-and long-term survival and prevalence of post operative ileus after small intestinal surgery in the horse. Equine Vet $J$ Suppl 32, 42-51.

Fubini SL. 1990. Intestinal adhesions. In: White NA, Moore JN (eds). Current Practice of equine Surgery. JB Lippincott, Philadelphia, USA, Pp 382-384.

Gilabert J. 2005. Expresión tisular de los componentes del sistema fibrinolítico y de las metaloproteinasas en la endometriosis. Tesis Doctoral, Facultad de Medicina, Universidad de Valencia, España.

Gorvy DA, GB Edwards, CJ Proudman. 2008. Intraabdominal adhesions in horses: a retrospective evaluation of repeat laparotomy in 99 horses with acute gastrointestinal disease. Vet J 175, 194-201.

Gupta S, PK Jain. 1985. Low-dose heparin in experimental peritonitis. Eur Sur Res 17, 167-172.

Hague BA, CM Honnas, BR Berridge, JL Easter. 1998. Evaluation of postoperative peritoneal lavage in standing horses for prevention of experimentally induced abdominal adhesions. Vet Surg 27, 122-126.

Hall LW, KW Clarke, CM Trim. 2001. Anaesthesia of the horse. In: Hall LW, Clarke KW, Trim CM (eds). Veterinary Anaesthesia. WB Saunders, London, UK, Pp 247-313.

Hanson RR, AJ Nixon, R Gronwall, D Meyer, J Pendergast. 1992. Evaluation of peritoneal fluid following intestinal resection and anastomosis in horses. Am J Vet Res 53, 216-221.

Hau T, RL Simmons. 1976. Anticoagulation in the treatment of experimental peritonitis. Surg Forum 27, 458.

Hau T, DH Ahrenholz, RL Simmons. 1979. Secondary bacterial peritonitis: the biologic basis of treatment. Curr Probl Surg 16, 1-65.

Hay WP, P Mueller. 1998. Intraabdominal adhesions. In: White NA, Moore JN (eds). Current Techniques in Equine Surgery and Lameness. WB Saunders, Philadelphia, USA, Pp 30-310.
Hay WP, E Mueller, B Harmon, L Amoroso. 2001. One percent sodium carboxymethylcellulose prevents experimentally induced abdominal adhesions in horses. Vet Surg 30, 223-227.

Hellebrekers BWJ, GCM Trimbos-Kemper, EA Bakkum, JBMZ Trimbos, PJ Declerck, T Kooistra, JJ Emeis. 2000. Short-term effect of surgical trauma on rat peritoneal fibrinolytic activity and its role in adhesion formation. Thromb Haemost 84, 876-881.

Herrick SA, SE Mutsaers, P Ozua, H Sulainam, A Omer, P Boulos, ML Foster, GJ Laurent. 2000. Human peritoneal adhesions are highly cellular, innervated, and vascularized. J Pathol 192, 67-72.

Ho WZ, JP Lai, XH Zhu, M Uvaydova, SD Douglas. 1997. Human monocytes and macrophages express substance $\mathrm{P}$ and neurokinin-1 receptor. J Immunol 159, 5654-5660.

Hollinshead W. 1953. Anatomic pathways for pain from the upper part of the abdomen. Mayo Clinic Proc 28, 385-394.

Holmdahl L. 1997. The role of fibrinolysis in adhesion formation. Eur J Sur Suppl 577, 24-31.

Holmdahl L, M Falkenberg, ML Ibarsson, B Risberg. 1997. Plasminogen activators and inhibitors in peritoneal tissue. Acta Path Micro Im 105, 25-30.

Hökfelt T, B Pernow, J Wahren. 2001. Substance P: a pioneer amongst neuropeptides. J Intern Med 249, 27-40.

Hudson NPH, MG Dunlop. 2005. Horses for courses. Comparative gastroenterology: common ground and collaborative potential. BMJ 331, 1248-1251.

Jansen R. 1988. Early laparoscopy after pelvic operations to prevent adhesions: safety and efficacy. Fertil Steril 49, 26-31.

Jennings JE. 1937. Drainage of the abdomen. Ann Surg 105, 67-73.

Johns A. 2001. Evidence-based prevention of postoperative adhesions. Hum Reprod Update 7, 577-579.

Kennedy R, DJ Costain, VC McAlister, TD Lee. 1996. Prevention of experimental postoperative peritoneal adhesions by $\mathrm{N}, \mathrm{O}-$ carboxymethylchitosan. Surgery 120, 866-870.

Kramer K, N Senninger, H Herbst, W Probst. 2002. Effective prevention of adhesions with hyaluronate. Arch Surg 137, 278-282.

Kuebelbeck KL, DE Slone, KA May. 1998. Effect of omentectomy on adhesions formation in horses. Vet Surg 27, 132-137.

Lai JP, SD Douglas, WZ Ho. 1998. Human lymphocytes express substance $\mathrm{P}$ and its receptors. J Neuroimmunol 86, 80-86.

Lansdowne JL, LP Bouré, SG Pearce, CL Kerr, JL Caswell. 2004. Comparison of two laparoscopic treatments for experimentally induced abdominal adhesions in pony foals. Am J Vet Res 65, 681-686.

Lehman EP, F Boys. 1940. The prevention of peritoneal adhesions with heparin. Ann Surg 111, 427-435.

Liakakos T, N Thomakos, PM Fine, C Dervenis, RL Young. 2001. Peritoneal adhesions: etiology, pathophysiology, and clinical significance. Dig Surg 18, 260-273.

Little D, A Brown, NB Campbell, AJ Moeser, JL Davis, AT Blikslager. 2007. Effects of the cyclooxygenase inhibitor meloxicam on recovery of ischaemia-injured equine jejunum. Am J Vet Res 68, 614-624.

Liu Y, XZ Shu, GD Prestwich. 2007. Reduced postoperative intraabdominal adhesions using Carbylan-SX, a semisynthetic glycosaminoglycan hydrogel. Fertil Steril 87, 940-948.

Lopes Ferreira MA, AC de Oliveira Dearo, A Welker Biondo, LF Pita Godin, P Iamaguti, A Thomassian, A Kohayagawa. 1999. Exame do fluido peritoneal e hemograma de eqüinos submetidos à laparotomia e infusão intraperitoneal de carboxymetilcelulose. Ciência Rural 29, 79-85

Lundin C, KE Sullins, NA White, MF Clem, RM Debowes, CA Pfeiffer. 1989. Induction of peritoneal adhesions with small intestinal ischaemia and distention in the foal. Equine Vet J 21, 451-458.

MacDonald MH, JR Pascoe, SM Stover, DM Meaghler. 1989. Survival after small intestinal resection and anastomosis in horses. Vet Surg $18,415-423$

Mahaffey EA, JN Moore. 1986. Erythrocyte agglutination associated with heparin treatment in three horses. J Am Vet Med Assoc 189, 1478-1480. 
Mair TS, GB Edwards. 2003. Strangulating obstructions of the small intestine. Equine Vet Educ 15, 192-199.

Mair TS, LJ Smith. 2005. Survival and complication rates in 300 horses undergoing surgical treatment of colic. Part 3: Long-term complications and survival. Eq Vet J 37, 310-314.

Markwardt F, HP Klocking. 1977. Heparin induced release of plasminogen activator. Hemostasis 6, 370-374.

Matsuda, S, N Se, H Iwata, Y Ikada. 2002. Evaluation of the antiadhesion potential of UV cross-linked gelatin films in a rat abdominal model. Biomaterials 23, 2901-2908.

Memisoglu K, K Saribeyoglu, S Pekmezci, T Karahasanoglu, B Sen, I Bayrak, S Arbak, S Sirvanci. 2006. Mesh fixation devices and formation of intraperitoneal adhesions. J Laparoendosc Adv Surg Tech 16, 439-444.

Metwali A, AM Blum, L Ferraris, JS Klein, C Fiocchi, JV Weinstock. 1994. Eosinophils within the healthy or inflamed human intestine produce substance $\mathrm{P}$ and vasoactive intestinal peptide. J Neuroimmunol 52, 69-78.

Morris DD. 1988. Medical therapy of colic. In: Gordon BJ, Allen D (eds). Colic Management in the Horse. Veterinary Medicine Publishing Co., Kansas, USA, Pp 201-212.

Moses VS, AL Bertone. 2002. Nonsteroidal anti-inflammatory drugs Vet Clin Equine 18, 21-37.

Mueller E, WP Hay, B Harmon, L Amoroso. 1998. Evaluation of a bioresorbable hyaluronate membrane for prevention of experimentally induced abdominal adhesions in horses. AAEP Proceedings 44, 260-262.

Mueller E, WP Hay, B Harmon, L Amoroso. 2000a . Evaluation of a bioresorbable hyaluronate-carboxymethylcellulose membrane for prevention of experimentally induced abdominal adhesions in horses. Vet Surg 29, 48-52.

Mueller E, BG Harmon, WP Hay, LM Amoroso. 2000. Effect of carboxymethylcellulose and a hyaluronate-carboxymethylcellulose membrane on healing of intestinal anastomoses in horses. Am J Vet Res 61, 369-374.

Mueller E. 2002. Advances in prevention and treatment of intraabdominal adhesions in horses. Clin Tech Equine Pract 1, 163-173.

Murphy DJ, LS Peck, CJ Detrisac, CW Widenhouse, EP Goldberg. 2002. Use of a high-molecular-weight carboxymethylcellulose in a tissue protective solution for prevention of postoperative abdominal adhesions in ponies. Am J Vet Res 63, 1448-1454.

Mutsaers SE, D Whitaker, JM Papadimitriou. 1996. Changes in the concentration of microvilli on the free surface of healing mesothelium are associated with alterations in surface membrane charge. J Pathol 180, 333-339.

Mutsaers SE. 2002. Mesothelial cells: their structure, function and role in serosal repair. Respirology 7, 171-191.

Mutsaers SE. 2004. The mesothelial cell. Int J Biochem Cell Biol 36 , 9-16.

Nieto JE, JR Snyder, NJ Vatistas, SJ Spier, L van Hoogmoed. 2003. Use of an active intraabdominal drain in 67 horses. Vet Surg 32, 1-7.

O'Leary JP, G Wickbom, S Cha, A Wickbom. 1988. The role of feces, necrotic tissue, and various blocking agents in the prevention of adhesions. Ann Surg 207, 693-698.

Orita H, JD Campeau, JA Gale, RM Nakamura, GS diZerega. 1986. Differential secretion of plasminogen activator activity by postsurgical activated macrophages. J Surg Res 41, 569-573.

Parker JE, SL Fibini, BD Car, HN Erb. 1987. Prevention of intraabdominal adhesions in ponies by low dose heparin therapy. Vet Surg $16,459-462$.

Parker JE, S Fubini, R Todhunter. 1989. Retrospective evaluation of repeat celiotomy in 53 horses with acute gastrointestinal disease. Vet Surg 18, 424-431

Peck LS, GT Fossum, EP Goldberg. 1995. Evaluation of CMC and HA solutions foe adhesiolysis. J Investigative Surg 8, 337-348.

Phillips TJ, JP Walmsley. 1993. Retrospective analysis of the results of 151 exploratory laparotomies in horses with gastrointestinal disease. Equine Vet $J$ 25, 427-431.
Polubinska A, M Winckiewicz, R Staniszewski, A Breborowicz, DG Oreopoulos. 2006. Time to reconsider saline as the ideal rinsing solution during abdominal surgery. Am J Surg 192, 281-285.

Reed KL, A Brent Fruin, KK Bishop-Bartolomei, AC Gower, M Nicolaou, AF Stucchi, SE Leeman, JM Becker. 2002. Neurokinin-1 receptor and substance P messenger RNA levels increase during intraabdominal adhesion formation. J Surg Res 108, 165-172.

Reed KL, AB Fruin, AC Gower, AF Stucchi, SE Leeman, JM Becker. 2004. A neurokin 1 receptor antagonist decreases postoperative peritoneal adhesion formation and increases peritoneal fibrinolytic activity. P Natl Acad Sci 101, 9115-9120.

Renckens R, JJT Roelofs, V de Waard, S Florquin, HR Lijnen, P Carmeliet, $\mathrm{T}$ van der Poll. 2005. The role of plasminogen activator inhibitor type 1 in the inflammatory response to local tissue injury. J Thromb Haemost 3, 1018-1025.

Risberg B. 1997. Adhesions: preventive strategies. Eur J Surg Supp $577,32-39$

Ritchie H, NA Booth. 1998. The distribution of the secreted and intracellular forms of plasminogen activator 2 (PAI-2) in human peripheral blood monocytes is modulated by serum. Thromb Haemost 79, 813-817.

Ritchie H, LA Robbie, S Kinghorn, R Exley, NA Booth. 1999. Monocyte plasminogen activator inhibitor 2 (PAI-2) inhibits u-PA-mediated fibrin clot lysis and is cross-linked to fibrin. Thromb Haemost 81 , 96-103.

Rosenberg RD, PS Damus. 1973. The purification and mechanism of action of human antithrombin-heparin cofactor. J Biol Chem 248 , 6490-6505.

Rosett W, G Hodges. 1980. Antimicrobial activity of heparin. J Clin Microbiol 11, 30-34.

Sanfilippo JS, RS Williams, MA Yussman, CL Cook, F Bissonnette. 1992. Substance P in peritoneal fluid. Am J Obstet Gynecol 166, 155-159.

Schneider RK, DJ Meyer, RM Embertson, DG Gentile, CD Buergelt. 1988. Response of pony peritoneum to four peritoneal lavage solutions. Am J Vet Res 49, 889-894.

Schneider A, J Bennek, K Olsen, J Wei $\beta$, W Schmidt, U Rolle. 2006. Experimental study evaluating the effect of a barrier method on postoperative intraabdominal adhesions. Dig Dis Sci 51, 566-570.

Scott-Coombes D, S Whawell, MN Vipond, J Thompson. 1995. Human intraperitoneal fibrinolytic response to elective surgery. $\mathrm{Br} J$ Surg 82, 414-417.

Semrad SD. 1999. Diseases of the peritoneum. In: Colahan PT, Mayhew IG, Merritt AM, Moore JN (eds). Equine Medicine and Surgery, Mosby, Missouri, USA, Pp 790-808.

Shayani V, C Siegert, P Favia. 2002. The role of laparoscopic adhesiolysis in the treatment of patients with chronic abdominal pain or recurrent bowel obstruction. JSLS 6, 111-114.

Singer ER, MA Livesey. 1997. Evaluation of exploratory laparotomy in young horses: 102 cases (1987-1992). J Am Vet Med Assoc 211, 1158-1162.

Sitter T, K Toet, P Quax, T Kooistra. 1999. Fibrinolytic activity of human mesothelial cells is counteracted by rapid uptake of tissue-type plasminogen activator. Kidney Int 55, 120-129.

Sjösten ACE, H Ellis, GAB Edelstam. 2004. Retrograde migration of glove powder in the human female genital tract. Hum Reprod 19 , 991-995.

Smith CL, BA Dowling, AJ Dart. 2005. Recent advances in equine abdominal surgery. Vet $J$ 170, 41-51.

Sortini D, C Feo, K Maravegias, P Carcoforo, E Pozza, A Liboni, A Sortini. 2006. Role of peritoneal lavage in adhesion formation and survival rate in rats: An experimental study. J Invest Surg 19, 291-297.

Southwood LL, GM Baxter, JM Hutchison, R Shuster. 1997. Survey of diplomates of the American College of Veterinary Surgeons regarding postoperative intraabdominal adhesion formation in horses undergoing abdominal surgery. J Am Vet Med Assoc 211, 1573-1576.

Stone WC. 1992. Drains, dressings, and external coaptation. In: Auer JA (ed). Equine Surgery. Saunders, Philadelphia, USA, Pp 104-113. 
Sulaiman H, G Gabella, C Davis, S Mutsaers, P Boulos. 2001. Presence and distribution of sensory nerve fibers in human peritoneal adhesions. Ann Surg 234, 256-261.

Sulaiman H, L Dawson, GJ Laurent, GJ Bellingan, SE Herrick. 2002. Role of plasminogen activators in peritoneal adhesion formation. Biochem Soc Trans 30, 126-131.

Sullins KE, TS Stashak, KN Mero. 1985. Evaluation of intestinal staples for end-to-end anastomosis of the small intestine in the horse. Vet Surg 14, 87-92.

Sullins KE. 1990. Intestinal adhesion reduction. In: White NA (ed). The Equine Acute Abdomen. Lea \& Febiger, Philadelphia, USA, Pp 245-250.

Sullins KE, NA White, CS Lundin, G Gaulin, RM Dabareiner. 1991. Treatment of ischemia induced peritoneal adhesions in foals. Vet Surg 20, 348.

Sullins KE, NA White, CS Lundin, R Dabareiner, G Gaulin. 2004. Prevention of ischaemia-induced small intestinal adhesions in foals. Equine Vet J 36, 370-375.

Tarhan OR, A Eroglu, R Cetin, A Ýnce, M Bulbul, Ý Altuntas. 2005. Effects of seprafilm on peritoneal fibrinolytic system. ANZ J Surg 75, 690-692.

Thompson J. 1998. Pathogenesis and prevention of adhesion formation. Dig Surg 15, 153-157.

Tomlinson JE, AT Blikslager. 2003. Role of nonsteroidal anti-inflammatory drugs in gastrointestinal tract injury and repair. J Am Vet Med Assoc 222, 946-951.

Tomlinson JE, BO Wilder, KM Young, AT Blikslager. 2004. Effects of flunixin meglumine or etodolac treatment on mucosal recovery of equine jejunum after ischaemia. Am J Vet Res 65, 761-769.

Tsai SW, JF Fang, CL Yang, JH Chen, LT Su, SH Jan. 2005. Preparation and evaluation of a hyaluronate-collagen film for preventing postsurgical adhesion. J Int Med Res 33, 68-76.

Türkçapar AG, C Ozarslan, E Erdem, C Bumin, N Erverdi, J Kutlay. 1995. The effectiveness of low molecular weight heparin on adhesion formation in expermiental rat model. Int Surg 80, 92-94.
Vachon AM, AT Fischer. 1995. Small intestinal herniation through the epiploic foramen: 53 cases (1987-1993). Equine Vet J 27, 373-370.

Valdez H, MK Wallace. 1980. Peritoneal lavage in the horse. Proc AAEP 26, 239-242.

Van der Wal JBC, J Jeekel. 2007. Biology of the peritoneum in normal homeostasis and after surgical trauma. Colorectal Dis 9, 9-13.

Vatistas NJ, JR Snyder, WD Wilson, C Drake, S Hildebrand. 1996. Surgical treatment for colic in the foal: 67 cases (1980-1992). Equine Vet J 28, 139-145.

Vela AR, JC Littleton, JP O’Leary. 1999. The effects of minidose heparin and low molecular weight heparin on peritonitis in the rat. Am Surg 65, 473-477.

Vrijland WW, NL Tseng, HJM Eijkman, WCJ Hop, JJ Jakimowicz, P Leguit, PS Stassen, DJ Swank, R Haverlag, HJ Bonjer, H Jeekel. 2002. Fewer intraperitoneal adhesions with use of hyaluronic acidcarboxymethylcellulose membrane. Ann Surg 235, 193-199.

Vural B, NZ Cantürk, N Esen, S Solakoglu, Z Cantürk, G Kirkali, C Sökmensüer. 1999. The role of neutrophils in the formation of peritoneal adhesions. Hum Reprod 14, 49-54.

Wang XC, CQ Gui, QS Zheng. 2003. Combined therapy of allantoin, metronidazole, dexamethasone on the prevention of intraabdominal adhesion in dogs and its quantitative analysis. World J Gastroenterol 9, 568-571.

White NA. 1993. Pathophysiology and prevention of abdominal adhesions. Proc Annu Am Coll Vet Surg Sci Meet, Pp 160-162.

White NA. 1999. Medical treatments. In: White NA, Edwards B (eds). Handbook of equine colic. Butterworth-Heinemann, Oxford, UK, Pp 41-61.

Williams J, D McHugh, R White. 1992. Use of drains in small animal surgery. In Practice 14, 73-81.

Young R, L, J Cota, G Zund, BA Mason, JM Wheeler. 1991. The use of an ammiontic membrane graft to prevent postoperative adhesions. Fertil Steril 55, 624-628.

Zhang Z, S Xu, X Zhou. 2006. Preventive effects of chitosan on peritoneal adhesion in rats. World J Gastroenterol 12, 4572-4577. 
